\title{
Compressive Behaviour of Novel Timber-Filled Steel Tubular (TFST) Columns
}

\author{
Hassan Karampour ${ }^{1}$, Mélanie Bourges ${ }^{2}$, Benoit P. Gilbert ${ }^{1}$, Andrew Bismire ${ }^{1}$, Henri Bailleres ${ }^{3}$, \\ and Hong Guan ${ }^{1}$ \\ ${ }^{1}$ School of Engineering and Built Environment, Griffith University, Gold Coast, QLD, Australia \\ ${ }^{2}$ Institut National des Sciences Appliquées de Lyon, Villeurbanne, France \\ ${ }^{3}$ Department of Agriculture and Fisheries, QLD Government, Brisbane, QLD, Australia
}

\begin{abstract}
Timber-filled steel tubular (TFST) columns are proposed and fabricated in this paper using a novel manufacturing method without using glue or mechanical anchoring devices. Stub $(L=200$ $\mathrm{mm}$ ) and slender ( $L=1500 \mathrm{~mm}$ ) TFST columns with low-grade and high-grade timber inserts are manufactured, and are tested in compression. Analytical expressions and finite element analyses (FEA) models are developed to explain the test results. Using the validated FEA models, slenderness curves are established, and boundaries for classification of stub and slender columns are defined. Results show that the stub columns reach the ultimate capacity predicted by the analytical expression within $1 \%$. The slender columns buckle at loads lower than the suggested analytical elastic composite buckling load. The FE stress analysis shows that in short and long columns the failure initiates in timber and steel, respectively. The average ultimate capacities of the tested stub and slender high-grade columns are found to be $29 \%$ and $24 \%$ higher than those of the low-grade columns, respectively. Results suggest that TFST columns can be a potential substitute for concrete-filled steel tubular (CFST) columns, due to the lightweight of timber infill and its high compressive strength in the fibre direction. Moreover, the proposed product may offer a market to the non-graded (low Modulus of Elasticity) sawn lumbers.
\end{abstract}




\section{Introduction}

Composite columns, typically made up of steel and concrete and normally referred to as concrete-filled steel tubular columns (CFST), have been widely used in mid to high-rise construction in the past decades [1, 2]. In these columns, the steel tubular profile of rectangular (RHS), square (SHS) or circular (CHS) cross-section, is filled with concrete. CFST columns are preferred to bare steel or concrete columns, mainly because in CFST, (a) the buckling of the outer steel is delayed due to the inward support provided by the concrete, as well as the friction between the steel and concrete, (b) the outer steel functions as a permanent formwork for the inner concrete, thus reducing the construction time and cost, and (c) the confined concrete exhibits a more ductile behaviour when compared to a non-confined concrete column [3-5]. Compared to concrete, timber is light (about four times lighter) and sustainable (as timber plantations can capture and store carbon in large amounts). Additionally, in the direction parallel to the grain, timber has a compressive strength similar to the one of normal concrete ( $\left.f_{c}^{\prime}=40-50 M P a\right)$. These characteristics make timber a promising candidate to replace concrete in CFST. In the manufacturing method proposed herein, the composite column performance is achieved by means of the inherent multi-directional expansion of timber through moisture absorption, and the corresponding developed friction between timber and steel.

Many researchers have studied the compressive response of CFSTs, using experimental [6, 7] and numerical $[8,9]$ methods. Recent studies are more focused on the fire [10,11] and seismic [12] performances of CFSTs. Other researchers have investigated the application of sustainable material, such as recycled-aggregate, in the concrete infill $[13,14]$. Only limited research has been conducted on the structural response of composite steel-timber systems [15-20] and even less on confined timber or timber filled steel tubular columns (TFST) [21-23]. Najm et al. [21] performed compressive tests on circular timber columns confined with carbon fibres. They investigated the effect of full (fully wrapped) and partial (spiral wraps) carbon fibre confinement on the ultimate compressive capacity of stub columns with length of $L=170 \mathrm{~mm}$ and diameter of $D=57 \mathrm{~mm}(L / D=3)$. They observed an increase in the axial capacity of $10-40 \%$ in the confined samples in comparison with a bare stub timber column. They also observed improvements in the axial stiffness of the confined columns. Zhang et al. [22] studied the compressive behaviour of cracked timber columns retrofitted with FRP sheets through physical experiments and finite element analyses (FEA). In their tests the FRP sheets were intermittently wrapped around timber columns of lengths $L=1800 \mathrm{~mm}$ and $900 \mathrm{~mm}$, with widths $(D)$ of 200 $\mathrm{mm}$ and $100 \mathrm{~mm}(L / D=9)$. Their results showed that through application of the FRP sheets, the confined cracked timber columns could recover their axial load-carrying capacity by up to $20 \%$ [22]. Ghazijahani et al. [23] investigated the compressive behaviour of composite columns made up of outer steel CHS, solid timber infill, and CFRP confinements. In their experimental study, composite columns of length $L=300 \mathrm{~mm}$ and diameter $D=76.2 \mathrm{~mm}(L / D=4)$ were tested. They compared results of a full timber infill with those of a cruciform infill TFST column with and without CFRP confinement. When compared to the bare timber columns, they reported up to $146 \%$ and $83 \%$ increase in capacity in CFRP and steel confined sample, and in those without CFRP confinement, respectively. 
Previous studies have shown improvements in compressive behaviour of confined timber. However, the limited existing studies on TFSTs were restricted in length (stub columns), likely due to fabrication constraints. This study aims to investigate the structural compressive behaviour of innovative timber-filled steel tubular (TFST) columns, in which the composite action between the timber and steel is ensured without using glue or mechanical anchoring devices, and to determine their suitability for use in mid-rise constructions. To do so, behaviours of short $(L / D=4)$ and long $(L / D=30)$ TFST columns under axial loading are experimentally investigated. Analytical and numerical (FE) methods are used to explain the experimental results. Using the validated FE models, a slenderness study of the proposed TFST columns is conducted. The fabrication method suggested and presented herein is simple and can be used to manufacture longer and wider TFST columns.

\section{Samples and the manufacturing method}

Short and long TFST columns with nominal lengths of $200 \mathrm{~mm}$ and $1500 \mathrm{~mm}$, respectively, were manufactured. The cross-section of the short and long TFST columns is shown in Fig. 1a, and is comprised of an outer $50 \mathrm{~mm} \times 1.6 \mathrm{~mm}$ SHS steel profile $(b / t=31.25)$ and four radiata pine (Pinus radiata) timber inserts. Each timber insert was cut to a nominal cross-sectional dimension of $24 \mathrm{~mm} \times 24 \mathrm{~mm}$, and was oven dried at $103^{\circ} \mathrm{C}$ for 48 hours such that its moisture content (MC) was almost reduced to zero. Once the timber had lost moisture and shrank, it was pressed into the SHS annulus using an adjustable steel clamp to form the manufactured stub TFST columns shown in Fig. 1b. The columns were then left in a temperature-controlled room (set at $22^{\circ} \mathrm{C}$ ) for more than four months, to allow the timber to reabsorb moisture. The expansion of the timber was restrained by the steel SHS, eventually creating friction between the two materials and generating composite action without the use of glue or mechanical fasteners.

To study the effect of the timber grade on the structural response of TFST columns, two sets, namely: (a) Low Modulus of Elasticity (MOE) group and (b) High MOE group were manufactured. In the Low MOE group, low quality sawn lumbers (with MOE < 9,000 MPa) which do not meet the minimum grade (MGP10) in the Australian Standard AS1720.1 [24] were used, whereas in the High MOE group, high quality sawn lumbers (MOE>16,000 MPa) were exploited to manufacture the columns. The proposed product may offer a market to the non-graded (low MOE) sawn lumbers. The low and high MOE groups are represented with letters $L$ and $H$, respectively, in this paper. All the short TFST columns (with both low and high MOE timber inserts) were manufactured from the same SHS steel batch, referred to as batch A. The same batch was used to manufacture the long column with low MOE timber inserts. A second batch, referred to as batch $\mathrm{B}$, was used to manufacture the long TFST columns with high MOE timber inserts.

Overall, 12 specimens, 6 stub and 6 slender TFST columns (3 low MOE and 3 high MOE in each length category) were manufactured and tested. The manufactured TFST samples and the associated material labels are represented in Table 1.

\section{Methodology}




\subsection{Material properties}

\section{Experimental method}

To obtain the structural behaviour and the corresponding material constitutive models of timber and steel, uni-directional tests were conducted. As in the manufacturing of the TFST columns, the timber was placed along its grain direction inside the SHS profiles, the mechanical properties (strength and static MOE) of each timber infill were determined from uniaxial compression tests parallel to the grain. $170 \mathrm{~mm}$ long samples with a nominal cross-section of $90 \mathrm{~mm} \times 35 \mathrm{~mm}$ were cut from the same timber boards as the inserts. Total of 14 samples, 6 from the low MOE group (represented with $L$ in Table 1) and 8 from the high MOE group (represented with $H$ in Table 1 ) were cut and tested. Unfortunately, the timber inserts (boards L16-18) used to fabricate the stub low MOE columns and one low MOE long column (LL1), were accidentally disposed after manufacturing the columns and material testing could not be performed.

The compression test set-up is shown in Fig. 2a. The samples were positioned between a fixed bottom platen and a top platen mounted on a spherical seat to enable a uniform pressure to be applied. The samples were tested in a $500 \mathrm{kN}$ MTS universal testing machine at a stroke rate of $5 \mathrm{~mm} / \mathrm{min}$ [5] to reach failure in about 4-5 mins. Two $50 \mathrm{~mm}$ gauge extensometers were mounted on opposite sides of the timber specimens to measure the static MOE of the timber samples, calculated as the average value obtained from the two extensometers. The strength of the samples was calculated as the ratio of the maximum load reached to the measured crosssectional dimensions.

The dynamic MOE of the timber infill was also measured using a non-destructive acoustic vibration test method using the BING software [25]. The vibration test method allows determination of the dynamic bending and compression MOE by analysing the natural vibration spectrum of a piece of wood [26].

The material properties of the steel were measured from uniaxial tensile coupons, water-jet cut from the flat parts of the SHS. Two coupon samples with gauge lengths of $120 \mathrm{~mm}$ were taken from each batch (A and B), and were tested in an Instron machine at a strain rate of 0.03 $\mathrm{mm} / \mathrm{mm} / \mathrm{min}$ [18]. Two strain gauges mounted on the opposite sides of the coupon sample were used to measure the strain.

\section{Analytical model}

Idealised material definitions can be used to predict constitutive material behaviours of timber and steel. A tri-linear material definition [27] could be used for timber, in which, the initial slope of the linear relation is obtained from the measured MOEs from compression tests. The secondary slope is obtained from curve-fitting of average yield and ultimate stresses, and the corresponding strains. The third slope of the descending line is found from a best-fit of the softening response from the tests.

Amongst the published material models for ductile steel, the one proposed by Ramberg-Osgood [28] is shown to better represent the physical behaviour, and is defined by the following powerlaw 
$\varepsilon_{s t}=\frac{\sigma_{s t}}{E}\left[1+\frac{3}{7}\left(\frac{\sigma_{s t}}{\sigma_{y}}\right)^{n-1}\right]$

where $\varepsilon_{s t}$ and $\sigma_{s t}$ are the strain and stress in the steel, respectively. $E$ is the Young's modulus of steel. Yield stress of the steel, $\sigma_{y}$, is the $0.2 \%$ yield proof of stress and $n$ is the power integer.

3.2 Stub columns

\section{Experimental method}

The stub columns with a length of $200 \mathrm{~mm}$ were tested in compression in a $500 \mathrm{kN}$ MTS universal testing machine using the test set-up shown in Fig. 2b. Prior to testing, the ends of the samples were milled flat to avoid stress concentration between the samples and the loading platens. The bottom platen was fixed while the top platen was pinned and lowered at a rate of $1 \mathrm{~mm} / \mathrm{min}$ to reach failure in about 3-4 mins. The axial force was recorded from the machine, and the axial shortening was obtained by finding the average of the two extensometer readings, which were positioned on the opposite faces of each column.

Immediately after testing, the samples were cut in strips and the timber infill was weighed to determine its moisture contents at various locations along the length of the TFST columns, following the oven-dry methodology in the Australian and New Zealand standard AS/NZS 1080.1 .

\section{Analytical model}

Using the idealised material definitions (Section 3.1), an analytical expression can be proposed to predict the axial response of the stub TFST columns. The analytical model is based on the compatibility assumption: i.e, during the axial compressive tests of the TFSTs, the strains in the steel and timber remain equal $\left(\varepsilon_{s t}=\varepsilon\right.$ tim). The stress-strain relationship in timber and steel follow their constitutive material definition. Therefore, the axial force in the stub TFST column $P_{\text {stub }}$ can be related to the constitutive stresses and strains of timber $\left(P_{t i m}\right)$ and steel $\left(P_{s t}\right)$, using the following expression:

$$
P_{\text {stub }}=P_{\text {st }}+P_{\text {tim }}=A_{\text {st }} \times \sigma_{\text {st }}+A_{\text {tim }} \times \sigma_{\text {tim }}
$$

where $\sigma_{\text {st }}$ and $\sigma_{\text {tim }}$ are the stresses in steel and timber and $A_{\text {st }}$ and $A_{\text {tim }}$ are the measured crosssection area of steel and timber, respectively.

\subsection{Slender columns}

\section{Experimental method}

Figure 3a shows the experimental set-up used to test the slender TFST columns with a length of $1500 \mathrm{~mm}$. To control the buckling mechanism of the columns, a pinned-pinned support condition in the plane of the buckle, and a fixed-support condition in the out-of-plane direction were adopted. To do so, a pin-end assembly (shown in Fig. 3b) made up of $20 \mathrm{~mm}$ thick steel plates at the top and bottom, and an inner solid rod (pin) passing through 6 triangular shear stiffeners was manufactured. The pin-assemblies were bolted onto a T-joint at one end (which 
was inserted into the jaw of the testing machine) and onto the column base plate at the other end. The column was epoxied into the base plate a shown in Fig. $3 \mathrm{~b}$.

To measure the buckle amplitude, a laser transducer was positioned at the mid-length of the column. Strain-gauges were attached to the mid-length of the column on the compression and tension sides to capture the axial-shortening as well as the post-buckle strains (Fig. 3a). Two LVDTs (shown in Fig. 3b) were connected to the top and bottom base plates to measure the relative vertical displacement between the two platens by taking the average values of the LVDT readings. The buckling response was captured by lowering the top jaw of the $500 \mathrm{kN}$ MTS universal testing machine at a constant rate of $1 \mathrm{~mm} / \mathrm{min}$ to reach failure in about 5 mins. Prior to the execution of each test, the out-of-straightness of the column was measured using a laser level aligner. The maximum measured out-of-straightness was $3 \mathrm{~mm}$ (i.e. $\delta / L=0.002$ ).

The moisture content of the timber within the tested slender TFST columns was measured one day after the tests. To determine the moisture content distribution along the TFST columns, timber samples were taken from the top, middle and bottom of the columns.

\section{Analytical model}

The axial stiffness of the slender TFST columns can be calculated from Eq. 2, assuming that the strains in steel and timber remain within the elastic region. Using non-dimensional parameters $n_{t}$ and $\mu$

$n_{t}=\frac{A_{t i m}}{A_{s t}} \quad, \quad \mu=\frac{E_{s t}}{E_{\text {tim }}}$

the following expression can be used to find the axial stiffness of the TFST columns (KTFST), based on the measured material properties

$$
k_{\text {TFST }}=\left(\frac{A_{s t} \times E_{s t}}{L}\right)\left(1+\frac{n_{t}}{\mu}\right)
$$

The column length, $L$, is measured from the centre to centre of the pin-end assemblies shown in Fig. 3b. The average measured $L$ of the slender columns was $1,580 \mathrm{~mm}$. The elastic column buckling capacity $\left(P_{e}\right)$ of the slender TFST columns can be obtained from the Euler expression:

$$
P_{e}=\frac{\pi^{2} E_{t i m} I_{e q}}{L^{2}}
$$

where $I_{e q}$ is the equivalent moment of inertia of the column using a transformed cross-section analogy (assuming the strains in timber and steel are equal).

\subsection{Finite element analysis (FEA)}

A FEA model is developed using ANSYS [29], and is validated against the experimental results of the short and long columns. In the model, the outer square-hollow-section SHS steel was meshed using four-node shell 181 elements with 5 integration points along the wall-thickness. The timber insert was meshed with eight-node solid 186 elements. Top and bottom rigid steel plates with thickness of 10 millimetres were attached at either ends of the columns and were 
used to impose the load and boundary constraints. A frictional contact surface with a coefficient of friction equal to 0.3 was defined between the SHS and the timber insert. A sensitivity analysis performed revealed that the axial-behaviour of the composite column is not significantly affected by the assumed coefficient of friction. A bonded contact was used to model the interface between the top/bottom plates and the column.

A bilinear isotropic material definition was adopted for steel with parameters shown in Table 2 , and with a tangent modulus equal to $1.5 \%$ of the MOE of steel. The bilinear definition was preferred to Ramberg-Osgood model due to its computational efficiency. The timber insert was modelled using elastic-plastic constitutive law in compression. The Hill yield criterion [30], which is an extended formulation of von-Mises criterion for anisotropic materials, was used to define the plastic behaviour of timber. The stress potential in the Hill criterion is expressed as

$$
\sigma_{e}=\sqrt{F_{33}\left(\sigma_{x}-\sigma_{y}\right)^{2}+F_{11}\left(\sigma_{y}-\sigma_{z}\right)^{2}+F_{22}\left(\sigma_{z}-\sigma_{x}\right)^{2}+2 N_{12} \tau_{x y}^{2}+2 N_{23} \tau_{y z}^{2}+2 N_{31} \tau_{x z}^{2}}
$$

where $F_{i i}(i=1,2,3)$ and $N_{i j}(i \neq \mathrm{j}=1,2,3)$ are constants obtained from the material tests conducted in different orientations

$$
\begin{aligned}
& F_{i j}=\left[\frac{\left(\sigma_{0}\right)^{2}}{2}\right]\left[\frac{1}{\left(\sigma_{j j}^{y}\right)^{2}}+\frac{1}{\left(\sigma_{k k}^{y}\right)^{2}}-\frac{1}{\left(\sigma_{i i}^{y}\right)^{2}}\right]=\frac{1}{2}\left[\frac{1}{R_{j j}{ }^{2}}+\frac{1}{{R_{k k}}^{2}}-\frac{1}{R_{i i}{ }^{2}}\right]\left\{\begin{array}{l}
i=1,2,3 \\
j=2,3,1 \\
k=3,2,1
\end{array}\right\} \\
& N_{i j}=\frac{3}{2}\left[\frac{\left(\tau_{0}\right)^{2}}{\sigma_{i j}^{y}}\right]=\frac{3}{2}\left[\frac{1}{{R_{i j}}^{2}}\right](i \neq j=1,2,3)
\end{aligned}
$$

where $\sigma_{i i}^{y}$ and $\sigma_{i j}^{y}$ correspond to the normal and shear yield stresses, and subscripts 1, 2 and 3, are associated with the longitudinal, tangential and radial directions, respectively. $R_{i j}$ are the yield ratios which relate the yield level for stress components $\sigma_{i j}^{y}$, to the reference yield stress $\sigma_{0}$ of the material. The yield ratios are defined as follows:

$$
\begin{aligned}
& R_{i j}=\left\{\begin{array}{ll}
\frac{\sigma_{i j}^{y}}{\sigma_{0}}, & \text { if } i=j \\
\frac{\sigma_{i j}^{y}}{\tau_{0}}, & \text { if } i \neq j
\end{array}\right\} \\
& \tau_{0}=\frac{\sigma_{0}}{\sqrt{3}}
\end{aligned}
$$

In the current FE study, $R_{11}=1, R_{22}=R_{33}=0.119, R_{12}=R_{13}=R_{23}=0.435$ are adopted [31]. The reference yield stress $\sigma_{0}$ and the tangent moduli $E_{L}$ of timber were taken from the trilinear material definition of the corresponding timber insert (see Figs. 4 and 5). 
A schematic view of the timber material definition used in the FEA is shown in Fig. 5c. The MOE of timber along the fibre direction (axial direction) was taken from the compressive test results. MOE in the radial and tangential directions were taken as 0.095 times the MOE in the fibre direction [31]. Poisson ratios of 0.372 and 0.31 were adopted [31]. The shear modulus in the major planes was taken as 0.082 times the MOE in the fibre direction [31], and the shear moduli in the weak plane was assumed to be $16 \%$ of that.

\section{Results and Discussion}

\subsection{Material testing}

\section{Experimental results}

The stress-strain curves obtained from the compressive tests performed on the timber samples are shown in Fig. 4. The corresponding average dynamic longitudinal MOE, static MOE and ultimate strengths, with coefficient of variations (CoVs), are represented in Table 2. As expected [26], the dynamic MOE is 7-9\% higher than the one obtained from mechanical tests. The average static MOE of the low MOE timber is about $60 \%$ lower than the one of the high MOE timber, and the ultimate strength of the low MOE timber is $40 \%$ lower than the high MOE timber. The measured static MOEs of the low MOE timber showed a large variation with a CoV of $25.4 \%$. The ultimate strengths, however, were more consistent with a CoV of $9.6 \%$. The average ultimate strengths of low and high MOE timber were $32.5 \mathrm{MPa}$ and $51.5 \mathrm{MPa}$, respectively. Moisture contents (MC) of the timber samples are included in Table 2 as well. The high MOE group had an average MC about 20\% higher than the low MOE.

Regarding the steel, the MOEs and the $0.2 \%$ yield stresses obtained from the tensile coupon tests of steel batches A and B, are also represented in Table 2, showing similar values for the two batches.

\section{Analytical results}

Tri-linear constitutive models of the timber boards are plotted against those obtained from the material tests of L02 and H12 in Fig. 5a, (for the sake of brevity only one timber sample from each strength group is selected and plotted). The idealised Ramberg-Osgood definition (Eq. 1) with $n=30$ and $\sigma_{y}$ taken from Table 2 are compared to the test results of A1 and A2 in Fig. 5b, with good agreement.

\subsection{Stub columns}

\section{Experimental results}

The manufactured stub TFST columns were weighed regularly. After almost three and a half months after manufacturing, weights of the samples remained constant. This suggested that the wood in the stub TFST sample had reached a balance with the relative humidity and temperature of its surrounding environment. The moisture content (MC) of low and high MOE stub TFST columns were measured immediately after the test (122 days post manufacturing) and results are presented in Table 3. The average MCs of both low and high MOE columns in Table 3 are almost equal and are $10 \%$ larger than those of timber itself obtained from the material tests summarised in Table 2. 
The force-strain response of the low MOE (SL) and high MOE (SH) stub TFST columns obtained from the tests are shown in Fig. 6a and 6b, respectively. At the ultimate loads, buckling of the steel was observed in both the SL and SH stub TFTS columns (see Fig. 2b). A comparison between the SL and SH column responses shown in Fig. 6 suggests that, the SL group depicts a more ductile behaviour. This can be explained by comparing the material behaviours of the low and high MOE timbers. As shown in Fig. 5a, the low MOE timber reached its ultimate stress at a larger strain compared to the high MOE timber. The average ultimate compressive strength of the SH columns is $240.3 \mathrm{kN}$ and is about $29 \%$ higher than the average of the SL columns (187 kN, Fig. 6).

\section{Analytical results}

The force-displacement relation calculated from the analytical model (Eq. 2) of high MOE sample SH is plotted in Fig. 6b. In the analytical model (Eq. 2), the material properties of H14 (Fig. 4b) and steel properties of A given in Table 2 are used. As shown in Fig. 6b, the loaddisplacement response of the analytical model and those of the test results are in good agreement. The ultimate load calculated from Eq. 2 for the $\mathrm{SH}$ columns is $\mathrm{P}_{\text {stub }}=237.3 \mathrm{kN}$. This is only $1 \%$ different from the average of the three ultimate loads measured in the experimental study.

\subsection{Slender columns}

\section{Experimental results}

The MC distribution of the two slender columns from each MOE category is presented in Table 4. The MC distributions suggest that the humidity had recovered better within the low MOE timber insert compared to the high MOE timber. The average MCs of long TFST columns presented in Table 4 are much lower than those of the stub columns represented in Table 2. This problem can be rectified by revising the manufacturing method. For instance, a perforation can be imposed in the middle of the cross-section within the timber inserts to facilitate the absorption of humidity.

The compression test results of the low and high MOE slender TFST columns are plotted in Fig. 7. Consistent stiffnesses (slopes of the linear segments of the curves) are observed in the tested samples of each MOE group. However, the ultimate loads are less consistent. From each group, one test showed larger buckling capacity, i.e LL2 in Fig. 7a and LH3 in Fig. 7b. This may be related to the lower moisture contents of LL2 and LH3 presented in Table 4.

\section{Analytical results}

Using Eq. 4, the axial stiffness ( $k_{T F S T}$ ) of the low and high MOE columns are calculated to be $46.5 \mathrm{kN} / \mathrm{mm}$ and $62.1 \mathrm{kN} / \mathrm{mm}$, respectively. These values are comparable to the corresponding experimental stiffnesses obtained from Fig. 7 of $48.3 \mathrm{kN} / \mathrm{mm}$ and $79.9 \mathrm{kN} / \mathrm{mm}$, respectively. It seems that Eq. 4 predicts the stiffness of the low MOE columns relatively well; whereas, the experimental stiffness of high MOE columns is greater than the value obtained from Eq. 4. This is probably due to the large variation of MC of the timber insert along the column length (Table 4). Indeed, in the derivation of the axial stiffness shown in Eq. 4, the MOE of timber 
was taken from the material testing results of Table 2, i.e. at a higher MC therefore a lower MOE than the ones in the columns [32].

Using Eq. 5, with the average MOEs in Table 2, bifurcation loads of $102.9 \mathrm{kN}$ and $123.9 \mathrm{kN}$ are calculated for the low and high MOE slender columns, respectively. These buckling loads are also shown in Fig. 7 with solid blue lines. Note that the elastic buckling capacity determined by Eq. 5 does not include geometric imperfections, and thus provides an upper bound of the experimental buckling forces. The average experimental ultimate buckling load of the high MOE slender columns is $24 \%$ larger than that of the low MOE columns. This ratio is equal to $20 \%$ based on the analytical predictions given by Eq. 5 .

\subsection{FEA results}

\section{Validation}

Deformed shapes of the stub and slender TFST columns obtained from the experiments and FEA are shown in Fig. 8 for different slenderness ratios $\lambda$ (discussed below). The failure modes obtained from the FEA are similar to the experimental observations. The numerical load-strain response of a SH stub column is shown in Fig. 6b, and agrees well with the experimental and theoretical (Eq. 5) results. The force-axial displacement results of the slender columns obtained from the FEA are shown in Fig. 7, demonstrating a snap-through buckle response similar to the one observed during the tests. Fig. 8 further indicates that the FEA buckle loads are less than 3\% different from those predicted by Eq. 5, which suggests that the buckling in the slender columns is elastic.

\section{Stress analysis}

A stress analysis of the short and long TFST columns with material properties represented in Table 5 is conducted using the validated FE models. The slenderness ratio of the square section is defined as

$$
\lambda=2 \sqrt{3} \frac{L}{D}
$$

where $D$ is the width of the section. To make the comparison meaningful, identical material properties of timber and steel in both short $(\lambda=14)$ and long column $(\lambda=110)$ are assumed. The load-displacement curves for both columns are shown in Fig. 9, on which five stress stages (iv) are also marked. The von-Mises stress normalised to the yield stress in steel $\left(\sigma_{V M} / \sigma_{y}\right)$, and the Hill-stress (Eq. 6) normalised to timber yield stress in timber $\left(\sigma_{e} / \sigma_{o}\right)$, for each stage are given in Table 5.

In the short column $(\lambda=14)$, the timber fails at stage ii (represented by the highlighted $\sigma_{e} / \sigma_{o}$ value of 1.027 in Table 5). Subsequently, the steel carries more stress due to its strain-hardening behaviour, until plastic buckling occurs at stage iv. A drop in the load capacity is observed after this stage, which is related to the progress of buckling in steel. In the long column $(\lambda=110)$, the stress in timber remains well below the failure limit in the pre-buckling region. The snapthrough buckling occurs at stage iii, where the steel has just reached its yield capacity 
(represented by the highlighted $\sigma_{V M} / \sigma_{y}$ value of 1.0 in Table 5). Following the initiation of the global buckle, the stress in timber rapidly grows due to the bending of the column.

\section{Slenderness curves}

To define a slenderness relationship for the low and high MOE columns, various TFST columns with different lengths were analysed using the validated FE models. In the low MOE columns, the average material properties of steel batch A and low MOE timber obtained from Table 2 were used. In the high MOE columns, those of steel batch B and high MOE timber from Table 2 were selected. The average yield stresses $\sigma_{0}$ of $24.19 \mathrm{MPa}$ and $42.53 \mathrm{MPa}$ for the low and high MOE timber inserts were adopted in all models, respectively. The ultimate axial compressive capacity of the TFST columns $\left(P_{n}\right)$ were obtained from the FEA. The results as a function of $P_{n}$ are shown in Fig. 10, where the horizontal axis is the slenderness ratio of a square section, $\lambda$, defined in Eq. 9, and the vertical axis is the normalised strength index, $S I$, defined in Eq. 10 [33]

$$
S I=\frac{P_{n}}{P_{o}} \quad \text { where } \quad P_{o}=A_{s t} \sigma_{y}+A_{t i m} \sigma_{o}
$$

For the sake of comparison, the experimental test results of the stub columns $(\lambda=14)$ and long columns $(\lambda=110)$ are also shown in Fig. 10. The discrepancies between the FEA and experimental $S I$ results, are due to the assumed average yield stresses of timber and steel in the FEA models. A polynomial of $3^{\text {rd }}$ degree curve-fit from all the FEA results is also displayed on the figure. The slenderness curve of both low and high MOE TFST columns depicts a contra-flexure point at about $\lambda=100$, which corresponds to $S I=0.55$. Beyond this slenderness ratio, an almost linear trend is observed in the slenderness curve. The stub column behaviour corresponds to the slenderness ratios of $\lambda<50$.

Yu et al. [33] conducted an experimental study on the performance of CFSTs with SHS profile of $100 \mathrm{~mm} \times 1.9 \mathrm{~mm}(b / t=52.6)$ with average yield strength of $404 \mathrm{MPa}$, and with concrete infill of cube strength $f_{c u}=121.6 \mathrm{MPa}$, and $E_{\text {concrete }}=42,600 \mathrm{MPa}$. They [33] reported the axial capacities of CFST columns with slenderness ratio $\lambda$, from 12 to 120 . The yield slenderness limit for a plate element is calculated as follows [34]

$$
\lambda_{e}=\frac{b}{t} \sqrt{\left(\frac{\sigma_{y}}{250}\right)}
$$

where $b$ and $t$ are the width and thickness of the flanges of the SHS profile used in the compressive member. Using Eq. (11), the corresponding slenderness limits are equal to $\lambda_{e}=67$ and 44, for the CFST [] and current TFST columns, respectively. Both of these values are larger than the yield slenderness limit $\lambda_{e y}=40$. This makes the comparison between the studied CFST [33] columns and existing TFST columns meaningful. The CFST results are compared against the TFST results in Fig. 10. It can be interpreted from this figure that at similar slenderness ratios, TFST columns exhibit higher strength. This is more evident for the stub TFST columns.

\section{Conclusions}


Timber filled steel tubular stub and slender columns were manufactured using a novel method, without using glue or mechanical anchoring devices. Two different grades of timber, namely; the low MOE (average MOE=6.7GPa) and the high MOE (average MOE=17.4GPa) were inserted inside the outer SHS profiles. The tested stub TFST columns reached the ultimate capacity predicted from the analytical expression. The low MOE stub TFSTs showed more ductile behaviour compared to the high MOE columns. However, the ultimate capacity of the stub columns with high MOE was in average $29 \%$ higher than the low MOE columns. The ultimate capacity and axial stiffness of tested slender high MOE columns were $24 \%$ and $63 \%$ higher than the low MOE columns. The material properties of the low grade timber showed great variations in stiffness and strengths. However, the stiffness and ultimate loads of the tested TFST columns made with low grade timber inserts were consistent. This can be related to the enhanced properties of timber in compression, once it is confined. The proposed TFST column may offer a market to the non-graded (low MOE) sawn lumbers.

Measurement of the moisture contents revealed that the humidity had travelled faster within the low MOE timber inserts than in the slender columns. The proposed analytical models were able to correctly predict the load-displacement response of the stub columns and the ultimate capacity of the slender columns. The agreement between the analytical and experimental results suggests that there is a good composite action in the manufactured TFST columns. However, this composite action may be lost if there are too much MC variation in the timber due to the mechano-absorptive effect [34].

Using the validated FEA models and adopting bilinear plasticity in steel and orthotropic plasticity in timber, stress analysis of the short and long columns was conducted. It was understood that in the short columns, failure occurred in timber, whereas in the long columns the timber remained intact prior to steel buckling. This suggests that the proposed TFST columns are suitable for mid-rise buildings where the column slenderness $\lambda$, is usually smaller than 150. A series of finite element analyses were conducted on various TFST columns with different lengths, and a slenderness curve of the manufactured composite cross-section was developed through curve-fitting. It was understood that the stub column behaviour corresponds to the slenderness ratios of $\lambda<50$. A comparison between present results of the TFST columns and the published results of high performance CFSTs revealed that a TFST column may have better strength index than the CFST column at similar slenderness ratio.

\section{References}

1. Han, Lin-Hai, Zhong Tao, and Wei Liu. "Concrete filled steel tubular structures from theory to practice [J]." Journal of Fuzhou University (Natural Sciences Edition) 6 (2001): 003.

2. Han, Lin-Hai, Wei Li, and Reidar Bjorhovde. "Developments and advanced applications of concretefilled steel tubular (CFST) structures: Members." Journal of Constructional Steel Research 100 (2014): 211-228.

3. Huang, C. S., et al. "Axial load behavior of stiffened concrete-filled steel columns." Journal of Structural Engineering 128.9 (2002): 1222-1230. 
4. Sakino, Kenji, et al. "Behavior of centrally loaded concrete-filled steel-tube short columns." Journal of Structural Engineering 130.2 (2004): 180-188.

5. Giakoumelis, Georgios, and Dennis Lam. "Axial capacity of circular concrete-filled tube columns." Journal of Constructional Steel Research 60.7 (2004): 1049-1068.

6. Han, Lin-Hai, Xiao-Ling Zhao, and Zhong Tao. "Tests and mechanics model for concrete-filled SHS stub columns, columns and beam-columns." Steel and Composite Structures 1.1 (2001): 51-74.

7. Han, L-H. "Tests on stub columns of concrete-filled RHS sections." Journal of Constructional Steel Research 58.3 (2002): 353-372.

8. Hatzigeorgiou, George D. "Numerical model for the behavior and capacity of circular CFT columns, Part I: Theory." Engineering Structures 30.6 (2008): 1573-1578.

9. Tao, Zhong, Zhi-Bin Wang, and Qing Yu. "Finite element modelling of concrete-filled steel stub columns under axial compression." Journal of Constructional Steel Research 89 (2013): 121-131.

10. Ding, J., and Y. C. Wang. "Experimental study of structural fire behaviour of steel beam to concrete filled tubular column assemblies with different types of joints." Engineering Structures 29.12 (2007): 3485-3502.

11. Han, Lin-Hai, et al. "Experimental study and calculation of fire resistance of concrete-filled hollow steel columns." Journal of structural engineering 129.3 (2003): 346-356.

12. Stephens, Max T., Dawn E. Lehman, and Charles W. Roeder. "Seismic performance modeling of concrete-filled steel tube bridges: tools and case study." Engineering Structures 165 (2018): 88-105.

13. Wang, Yuyin, Jie Chen, and Yue Geng. "Testing and analysis of axially loaded normal-strength recycled aggregate concrete filled steel tubular stub columns." Engineering Structures 86 (2015): 192212.

14. Chen, Jie, et al. "Behavior of normal-strength recycled aggregate concrete filled steel tubes under combined loading." Engineering Structures 130 (2017): 23-40.

15. Loss, Cristiano, Maurizio Piazza, and Riccardo Zandonini. "Connections for steel-timber hybrid prefabricated buildings. Part I: Experimental tests." Construction and Building Materials 122 (2016): 781-795.

16. Loss, Cristiano, and Andrea Frangi. "Experimental investigation on in-plane stiffness and strength of innovative steel-timber hybrid floor diaphragms." Engineering Structures 138 (2017): 229-244.

17. Li, Zheng, et al. "Finite element modeling and parametric analysis of timber-steel hybrid structures." The Structural Design of Tall and Special Buildings 23.14 (2014): 1045-1063.

18. Hassanieh, A., H. R. Valipour, and M. A. Bradford. "Experimental and numerical study of steeltimber composite (STC) beams." Journal of Constructional Steel Research 122 (2016): 367-378.

19. Hassanieh, A., H. R. Valipour, and M. A. Bradford. "Load-slip behaviour of steel-cross laminated timber (CLT) composite connections." Journal of Constructional Steel Research 122 (2016): 110-121.

20. Hassanieh, A., H. R. Valipour, and M. A. Bradford. "Experimental and analytical behaviour of steeltimber composite connections." Construction and Building Materials 118 (2016): 63-75. 
21. Najm, Husam, Jerame Secaras, and Perumalsamy Balaguru. "Compression tests of circular timber column confined with carbon fibers using inorganic matrix." Journal of materials in civil engineering 19.2 (2007): 198-204.

22. Zhang, Weiping, et al. "Compressive behavior of longitudinally cracked timber columns retrofitted using FRP sheets." Journal of Structural Engineering 138.1 (2011): 90-98.

23. Ghazijahani, Tohid Ghanbari, Hui Jiao, and Damien Holloway. "Timber filled CFRP jacketed circular steel tubes under axial compression." Construction and Building Materials 94 (2015): 791-799.

24. Standard, Australian. "AS1720. 1—timber structures—part 1: design methods." Standards Australia (2010).

25. Baillères, Henri, et al. "Strength and stiffness assessment technologies for improving grading effectiveness of radiata pine wood." BioResources 7.1 (2012): 1264-1282.

26. Brancheriau, Loïc, and Henri Baillères. "Use of the partial least squares method with acoustic vibration spectra as a new grading technique for structural timber." Holzforschung 57.6 (2003): 644652.

27. Oudjene, M., and M. Khelifa. "Elasto-plastic constitutive law for wood behaviour under compressive loadings." Construction and Building Materials 23.11 (2009): 3359-3366.

28. Ramberg, W., and W. Osgood. "Description of strain-stress curves by three parameters." NACA TN 902 (1943).

29. ANSYS ${ }^{\circledR}$ Academic Research Mechanical, Release 18.1

30. R. Hill. "The mathematical theory of plasticity”. Oxford University Press, Oxford (NY) (1950).

31. R.J. Ross. "Wood handbook: wood as an engineering material”, vol. 509, USDA Forest Service, Forest Products Laboratory (2010), p. 1. General Technical Report FPL-GTR-190

32. O'Ceallaigh, Conan, et al. "An investigation of the viscoelastic creep behaviour of basalt fibre reinforced timber elements." Construction and Building Materials 187 (2018): 2

33. Yu, Qing, Zhong Tao, and Ying-Xing Wu. "Experimental behaviour of high performance concretefilled steel tubular columns." Thin-Walled Structures 46.4 (2008): 362-370.

34. Trahair, Nick, and Mark A. Bradford. Behaviour and Design of Steel Structures to AS4100: Australian. CRC Press, 2017. 
Table 1. Material used in the fabrication of the TFST columns

\begin{tabular}{|c|c|c|c|}
\hline & $\begin{array}{c}\text { TFST } \\
\text { sample }\end{array}$ & Timber insert & Steel batch \\
\hline \multirow{6}{*}{ 营 } & SL1 & & \\
\hline & SL2 & L16 & A \\
\hline & SL3 & & \\
\hline & SH1 & & \\
\hline & SH2 & H14 & A \\
\hline & SH3 & & \\
\hline \multirow{6}{*}{$\begin{array}{l}\text { 离 } \\
\text { 离 } \\
\frac{0}{\omega}\end{array}$} & LL1 & L17 \& L18 & \\
\hline & LL2 & L6 \& L7 & A \\
\hline & LL3 & L1 \& L2 & \\
\hline & LH1 & H8 \& H9 & \\
\hline & LH2 & H10 \& H11 & B \\
\hline & LH3 & H12 \& H15 & \\
\hline
\end{tabular}

Note: Average area of timber insert $A_{\text {tim }}=2,186 \mathrm{~mm}^{2}(\mathrm{CoV}=0.08 \%)$, Area of steel $\mathrm{A}_{\mathrm{st}}=309 \mathrm{~mm}^{2}$ 
Table 2. Mechanical properties of timber and steel obtained from tests

\begin{tabular}{|c|c|c|c|c|c|c|}
\hline ID & $\begin{array}{c}\text { Average density } \\
\text { of timber } \\
(\mathrm{kg} / \mathrm{m} 3)\end{array}$ & $\begin{array}{c}\text { Average } \\
\text { MC } \\
\%\end{array}$ & $\begin{array}{l}\text { Average } \\
\text { dynamic } \\
\text { longitudinal } \\
\text { MOE } \\
\text { (MPa) }\end{array}$ & $\begin{array}{c}\text { Average } \\
\text { static MOE } \\
\text { (MPa) }\end{array}$ & $\begin{array}{c}\text { Average } \\
\text { ultimate compressive } \\
\text { strength } \\
\text { (MPa) }\end{array}$ & $\begin{array}{c}\text { Average } \\
0.2 \% \text { yield stress } \\
\sigma_{\mathrm{y}}(\mathrm{MPa})\end{array}$ \\
\hline Low MOE & 704.5 (20.0\%) & $8.3(2.1 \%)$ & 6,712 (17.7\%) & $6,254(25.4 \%)$ & 32.54 (9.6\%) & - \\
\hline High MOE & 642.0 (3.0\%) & $9.8(1.6 \%)$ & 17,404 (3.5\%) & $15,874(6.1 \%)$ & 51.51 (7.4\%) & - \\
\hline A & - & - & - & 195,058 (0.15\%) & & 456.8 (0.57\%) \\
\hline B & - & - & - & 208,554 (1.67\%) & & $495.8(0.53 \%)$ \\
\hline
\end{tabular}

$* \mathrm{CoV}$ is given in brackets. 
Table 3: Moisture contents (MC) of the stub TFST columns

\begin{tabular}{|c|c|c|c|c|c|c|c|c|c|}
\hline & & & & & & & & Average & $\mathrm{CoV}$ \\
\hline L1 & L2 & L3 & L4 & L5 & L6 & L7 & & \multirow{2}{*}{$11 \%$} & \multirow{2}{*}{$12 \%$} \\
\hline $10 \%$ & $10 \%$ & $10 \%$ & $10 \%$ & $13 \%$ & $10 \%$ & $12 \%$ & & & \\
\hline H8 & H9 & H10 & H11 & H12 & H13 & H14 & H15 & \multirow{2}{*}{$10 \%$} & \multirow{2}{*}{$6 \%$} \\
\hline $11 \%$ & $10 \%$ & $10 \%$ & $11 \%$ & $10 \%$ & $11 \%$ & $11 \%$ & $10 \%$ & & \\
\hline
\end{tabular}

Table 4: Moisture contents (MC) distribution of the slender TFST columns

\begin{tabular}{cccc}
\hline TFST & Top & Middle & Bottom \\
\hline LL2 & $6.3 \%$ & $5.1 \%$ & $6.5 \%$ \\
LL3 & $7.4 \%$ & $4.2 \%$ & $7.8 \%$ \\
LH1 & $6.9 \%$ & $1.3 \%$ & $67 \%$ \\
LH3 & $5.5 \%$ & $0.9 \%$ & $5.4 \%$ \\
\hline
\end{tabular}


Table 5. FEA stress analysis of short $(\lambda=14)$ and long $(\lambda=110)$ TFST columns (see Fig. 9)

\begin{tabular}{|c|c|c|c|c|c|c|c|c|c|c|c|c|c|c|c|}
\hline \multirow[b]{2}{*}{ TFST } & \multirow[b]{2}{*}{$\begin{array}{l}\mathrm{MOE}_{\mathrm{Tim}} . \\
(\mathrm{MPa})\end{array}$} & \multirow[b]{2}{*}{$\begin{array}{c}\sigma_{0} \\
(\mathrm{MPa})\end{array}$} & \multirow[b]{2}{*}{$\begin{array}{l}\mathrm{MOE}_{\mathrm{St}} . \\
(\mathrm{MPa})\end{array}$} & \multirow[b]{2}{*}{$\begin{array}{c}\sigma_{Y} \\
(\mathrm{MPa})\end{array}$} & \multicolumn{2}{|c|}{$\mathrm{i}$} & \multicolumn{2}{|c|}{ ii } & \multicolumn{2}{|c|}{ iii } & \multicolumn{2}{|c|}{ iv } & \multicolumn{2}{|c|}{$\mathrm{v}$} & \multirow[b]{2}{*}{ Failure mode } \\
\hline & & & & & $\frac{\sigma_{V M}}{\sigma_{Y}}$ & $\frac{\sigma_{e}}{\sigma_{0}}$ & $\frac{\sigma_{V M}}{\sigma_{Y}}$ & $\frac{\sigma_{e}}{\sigma_{0}}$ & $\frac{\sigma_{V M}}{\sigma_{Y}}$ & $\frac{\sigma_{e}}{\sigma_{0}}$ & $\frac{\sigma_{V M}}{\sigma_{Y}}$ & $\frac{\sigma_{e}}{\sigma_{0}}$ & $\frac{\sigma_{V M}}{\sigma_{Y}}$ & $\frac{\sigma_{e}}{\sigma_{0}}$ & \\
\hline$\lambda=14$ & 14,710 & 40.77 & 195,600 & 456 & 0.443 & 0.363 & 1.002 & 1.027 & 1.010 & 1.233 & 1.014 & 1.247 & 1.050 & 1.189 & $\begin{array}{c}\text { Timber in stage } \\
\text { ii }\end{array}$ \\
\hline$\lambda=110$ & 14,710 & 40.77 & 195,600 & 456 & 0.258 & 0.205 & 0.735 & 0.265 & 1.000 & 0.890 & 1.026 & 1.25 & N/A & N/A & $\begin{array}{l}\text { Steel in stage } \\
\text { iii }\end{array}$ \\
\hline
\end{tabular}




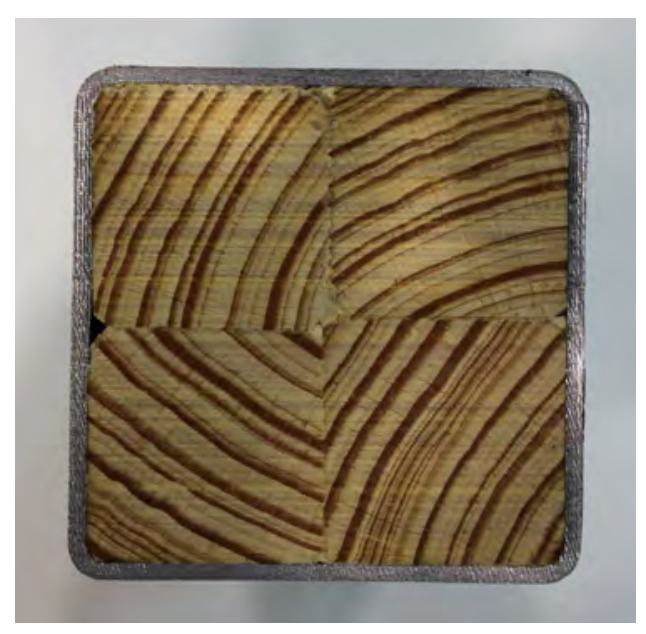

$50 \mathrm{~mm} \times 1.6 \mathrm{~mm}$ SHS

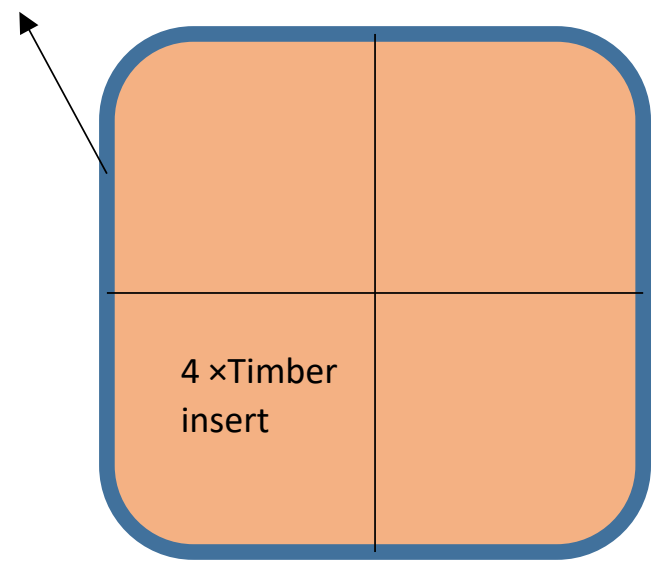

a

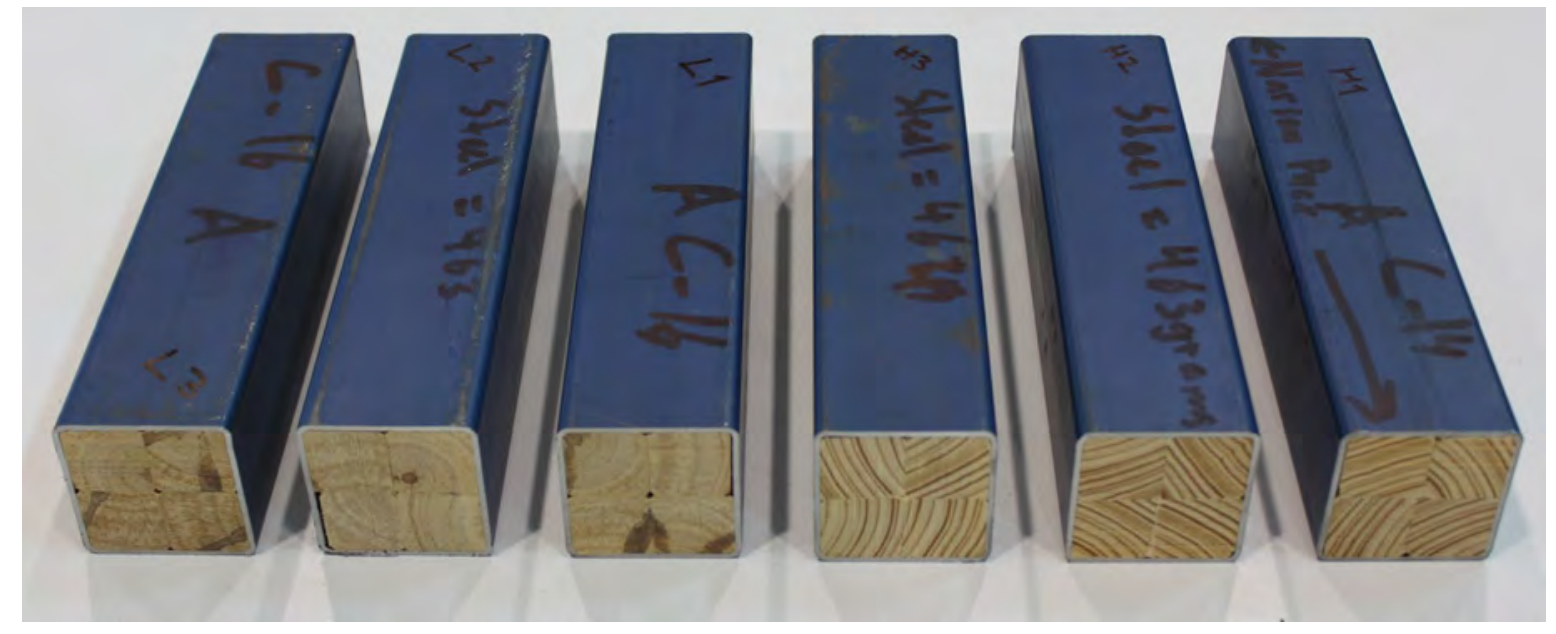

b

Figure 1. (a) Cross-section of the TFST columns, and (b) Stub TFST columns 

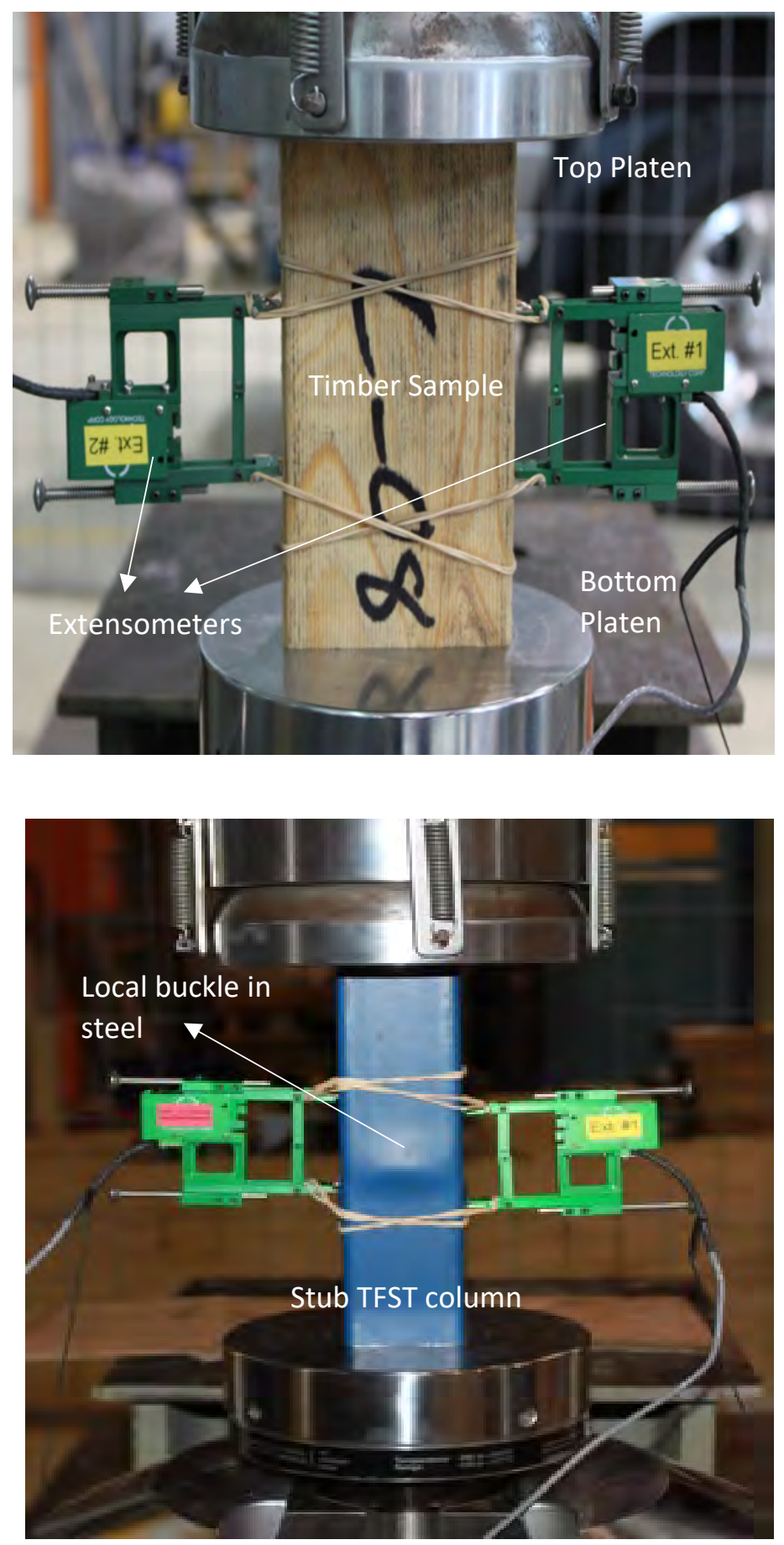

Figure 2. Compression test set-up to measure: (a) mechanical properties of the timber, and (b) axial response of the stub TFST columns 


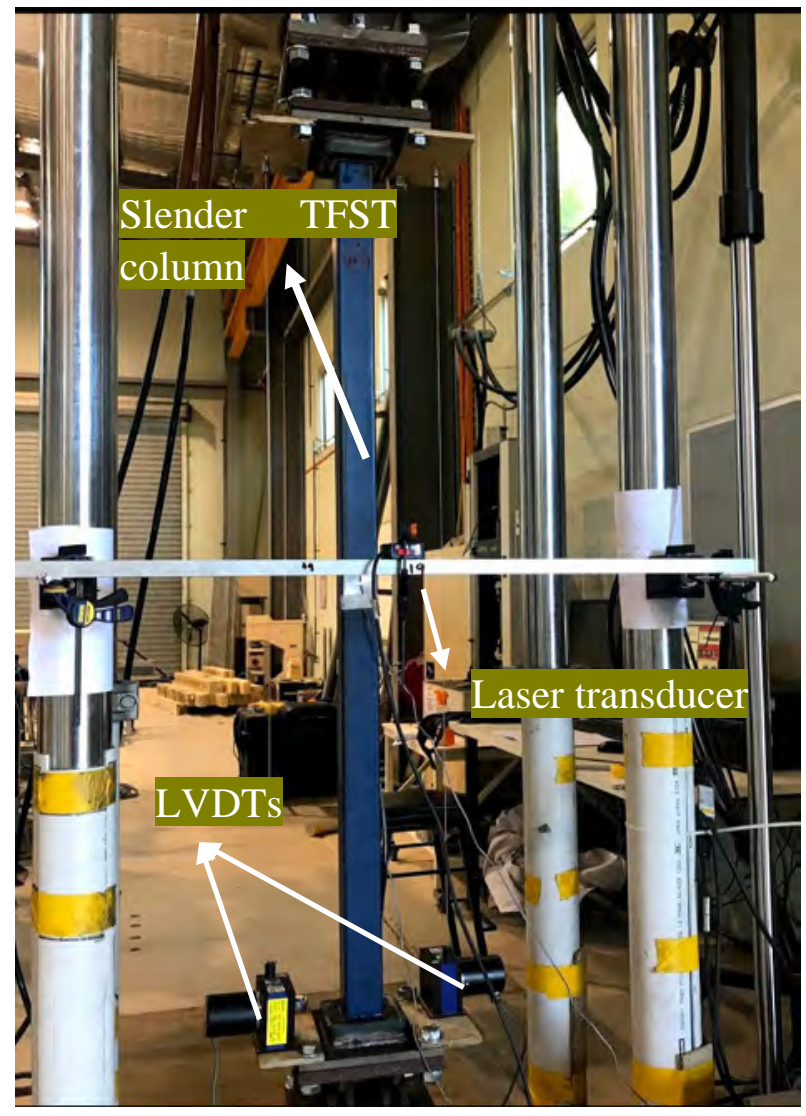

a

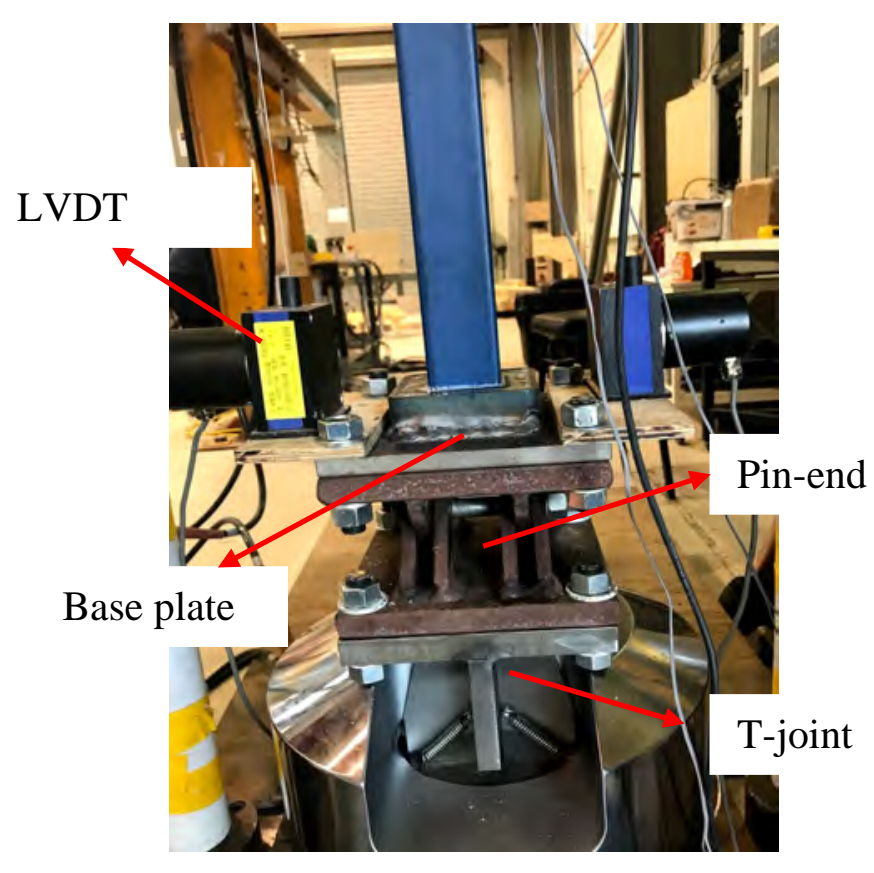

b

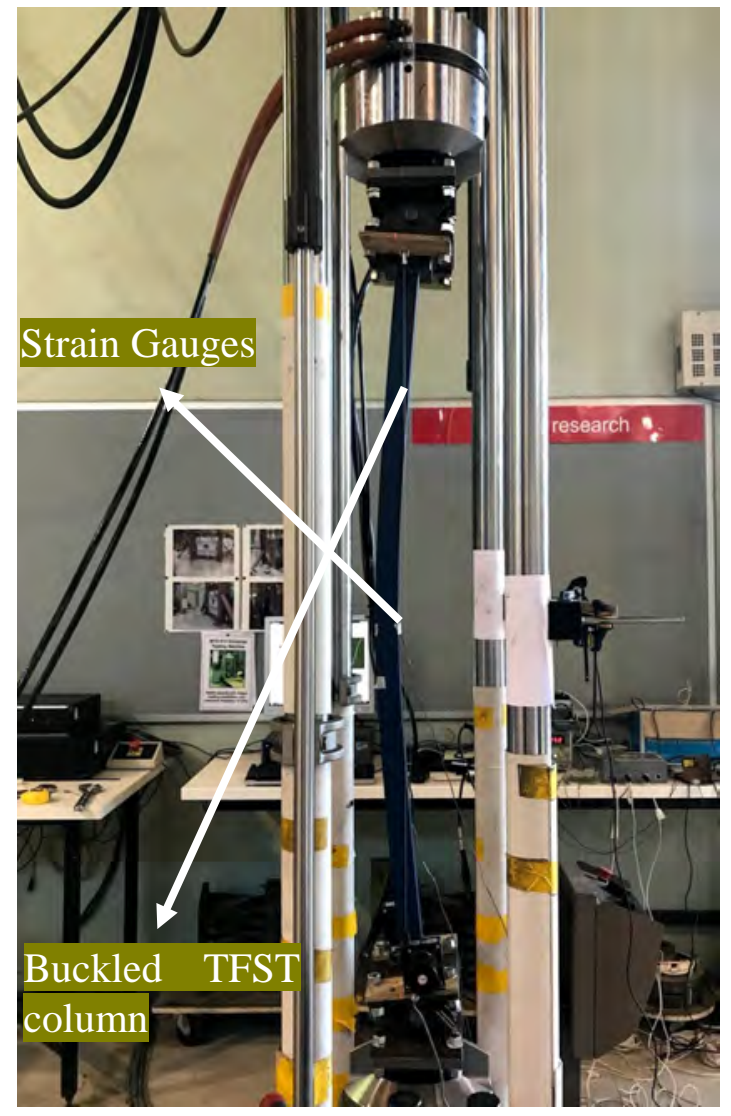

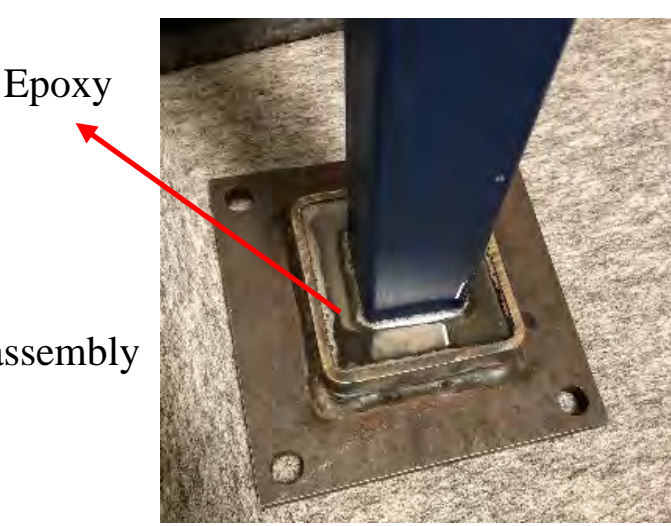

Base plate

Figure 3. Compression test of slender TFST columns: (a) test set-up showing the column before and after, and (b) the pin-end assembly. 

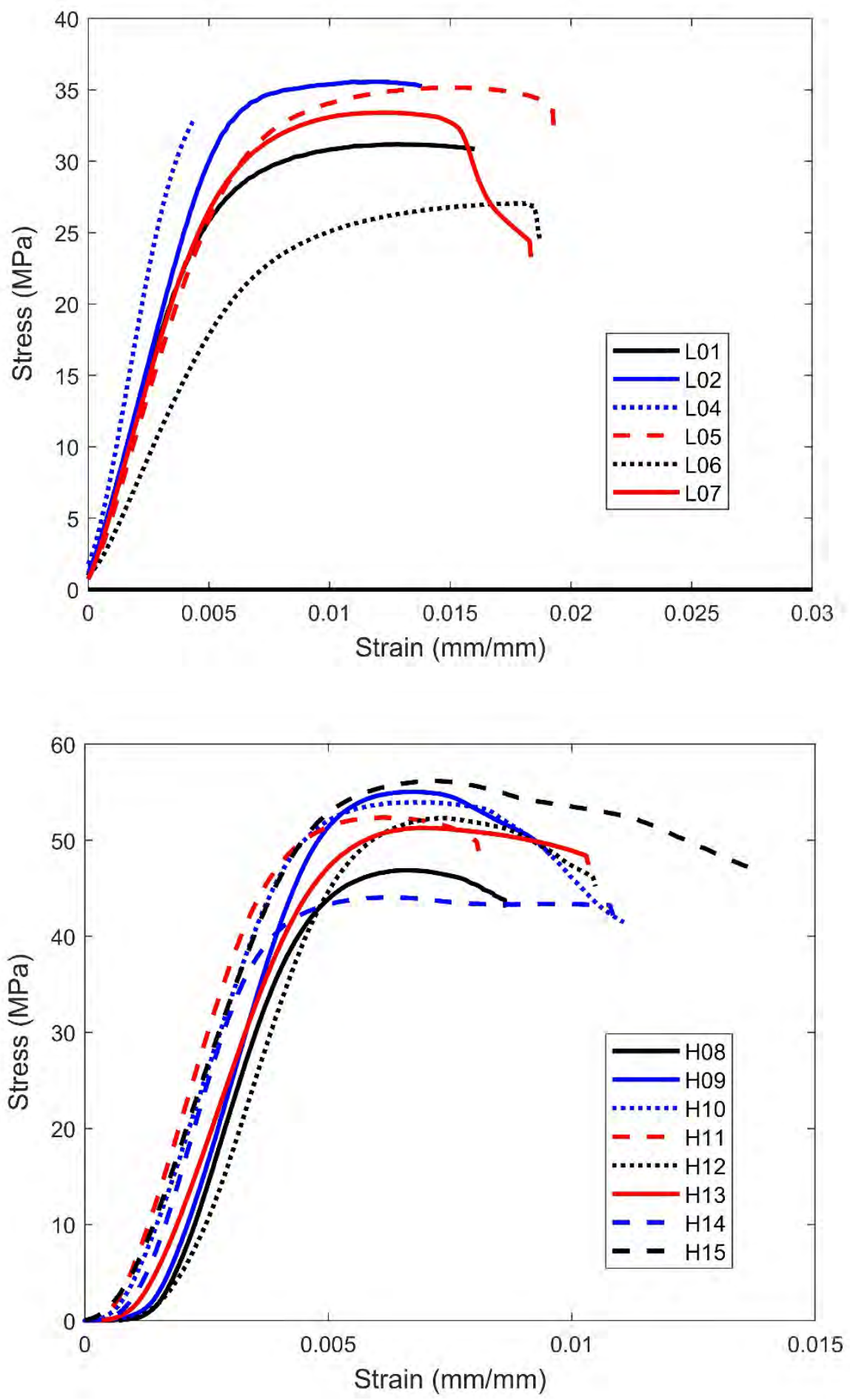

Figure 4. Compression test results of timber, (a) Low MOE, and (b) High MOE. 

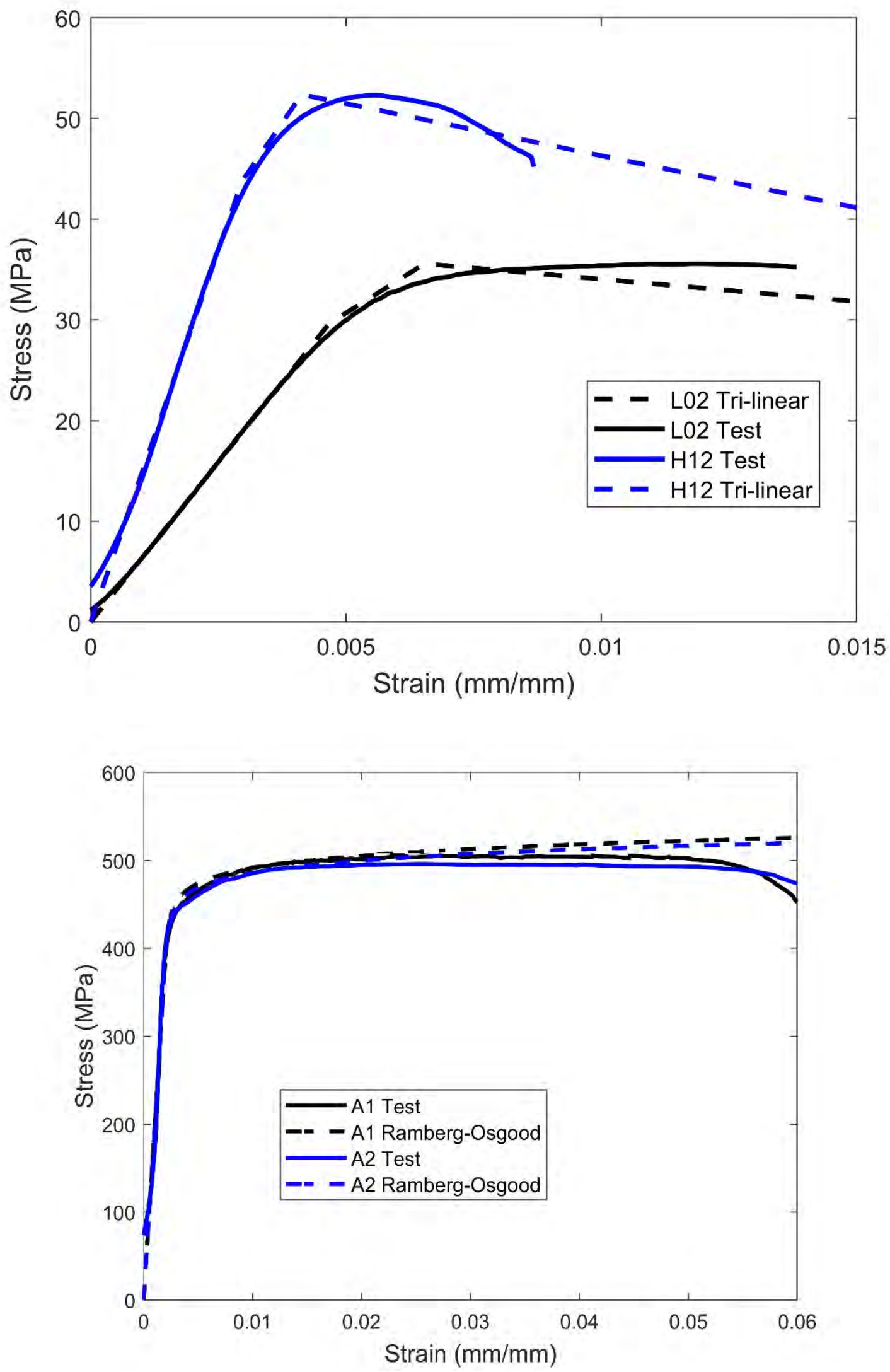

(b) 


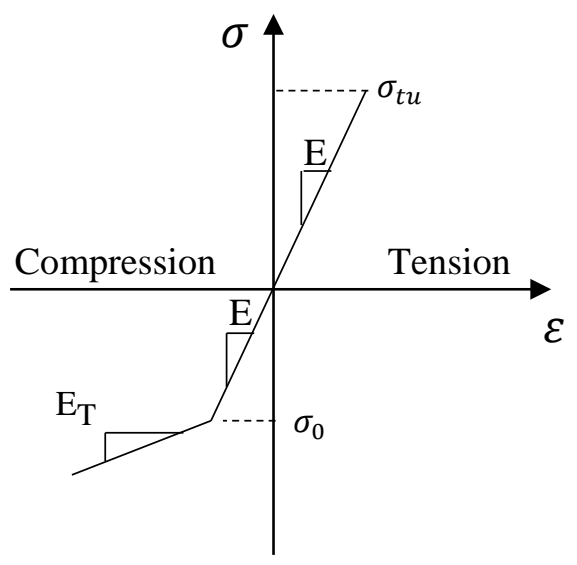

(c)

Figure 5. Idealised material models, (a) tri-linear definition for timber, (b) Ramberg-Osgood for steel, and (c) the stress-strain relationship of the timber insert adopted in the FE analysis 


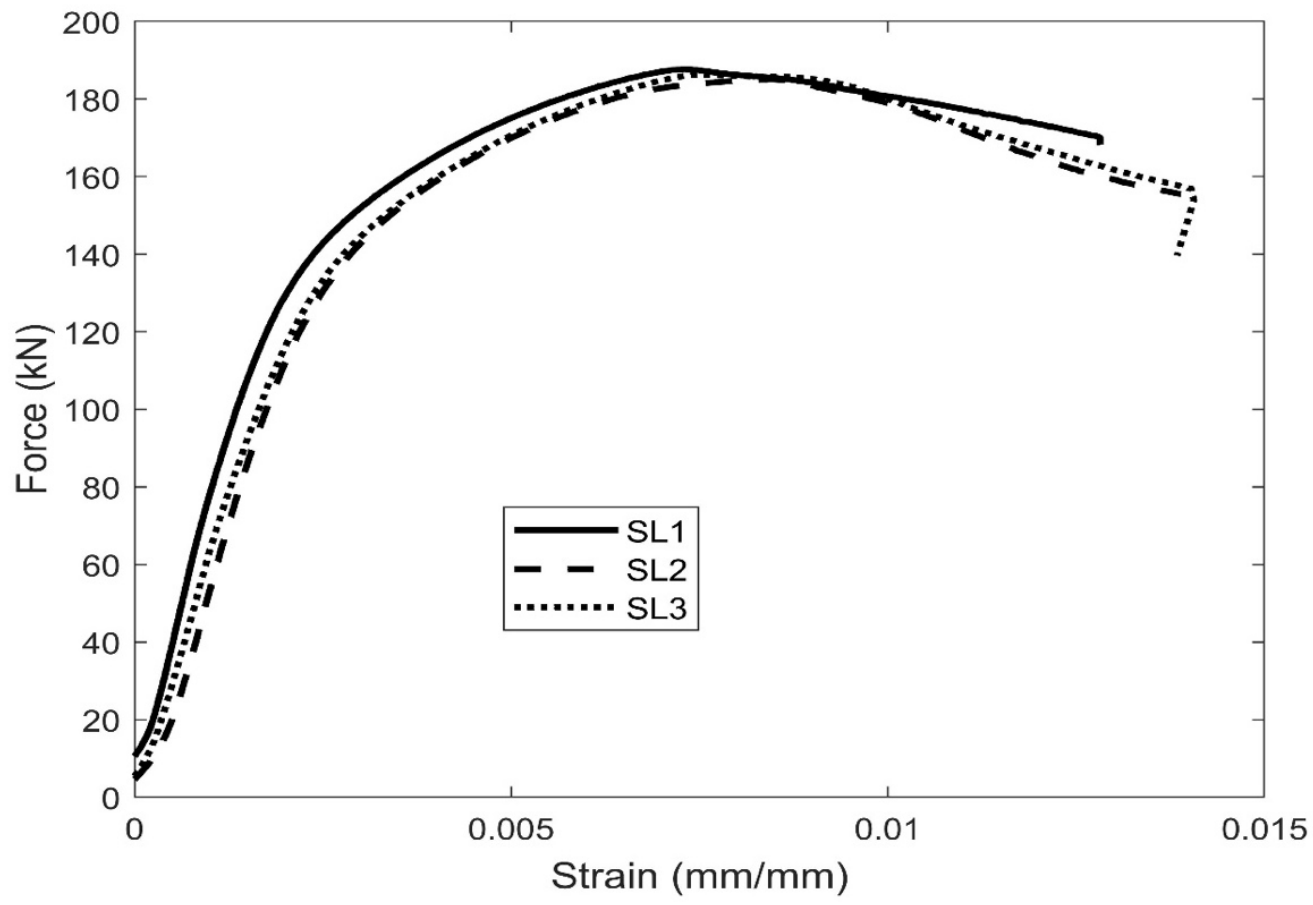

a

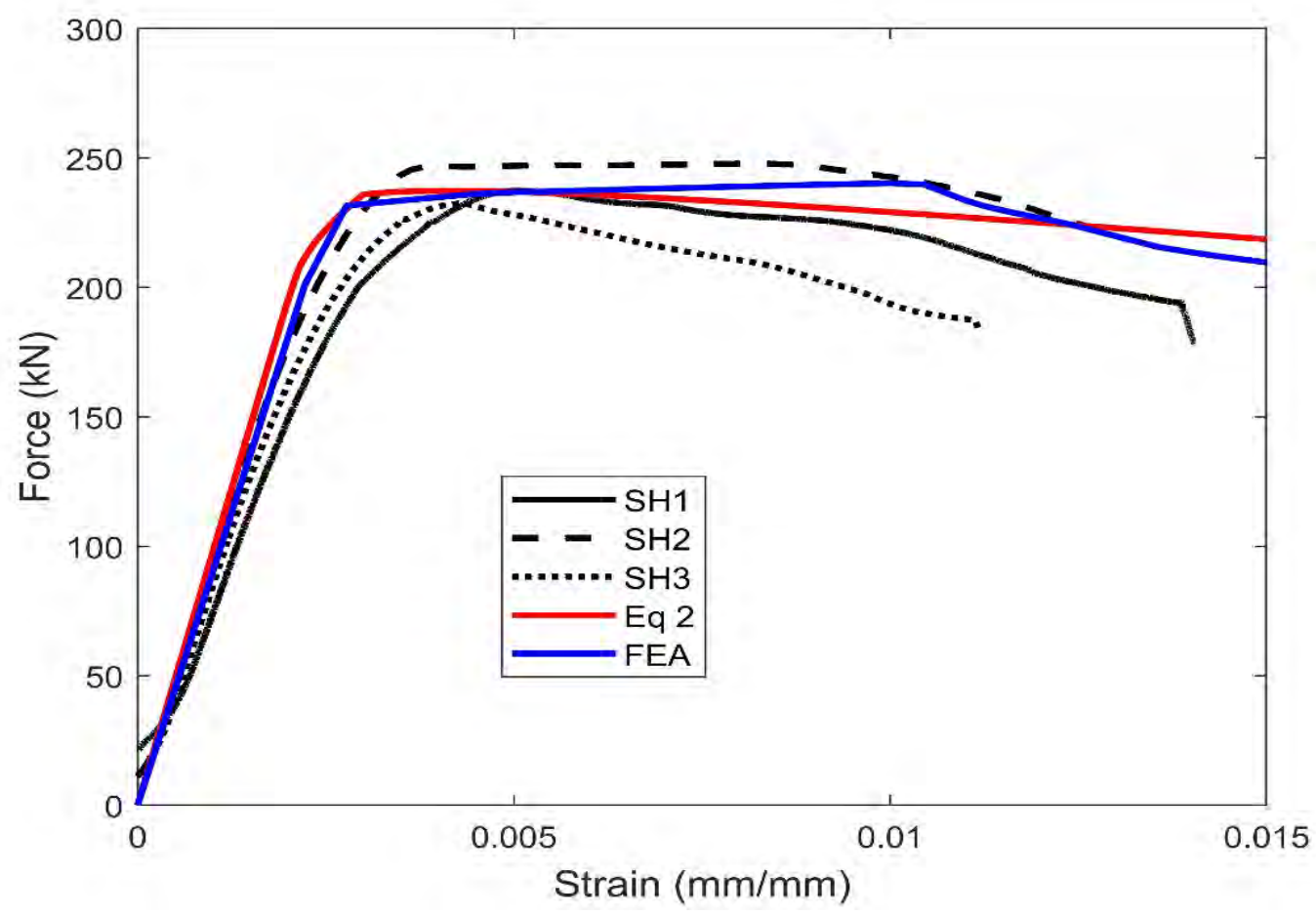

$\mathrm{b}$

Figure 6. Compression test results of stub TFST columns, (a) Low MOE, and (b) High MOE, showing the analytical and FEA results. 


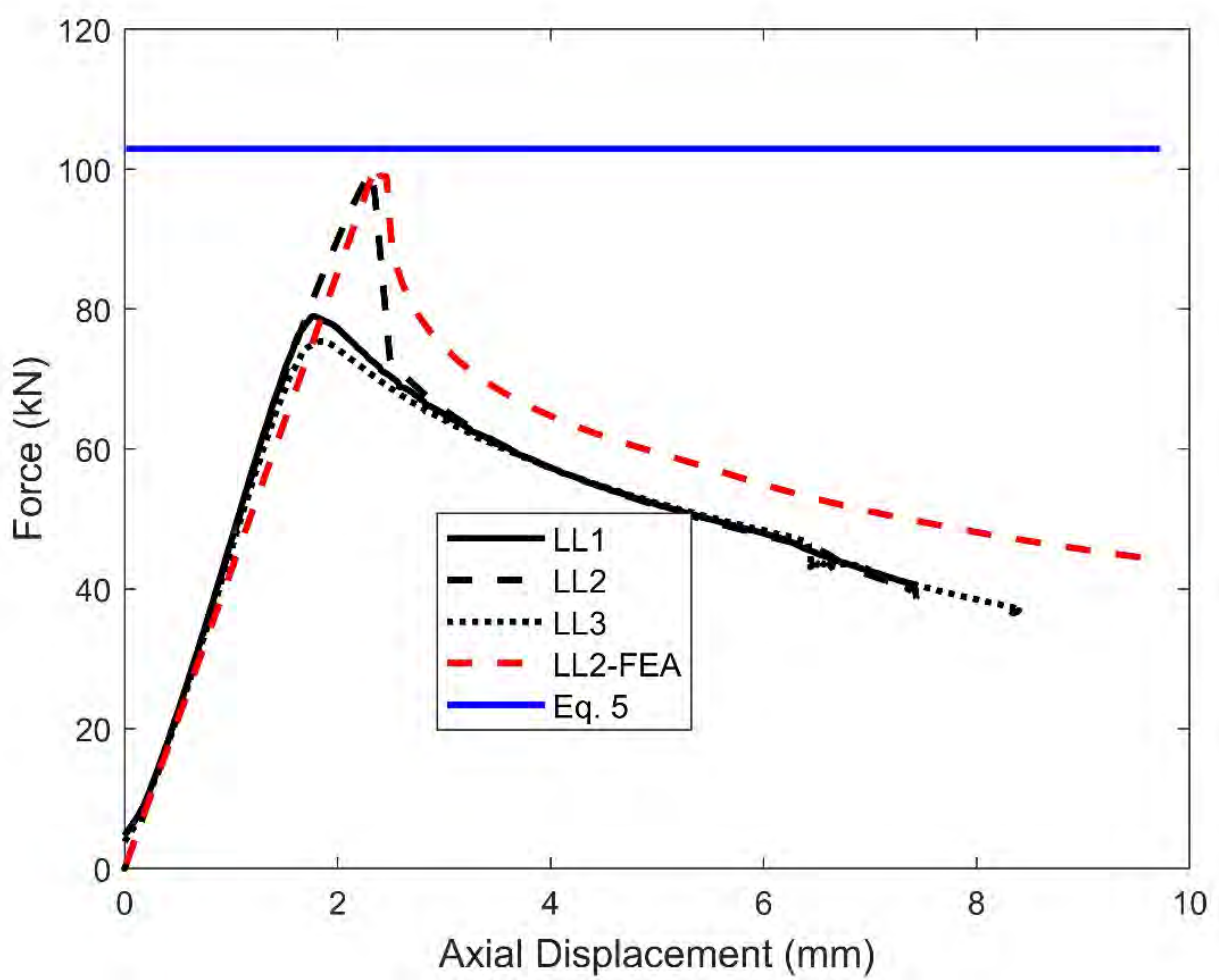

a

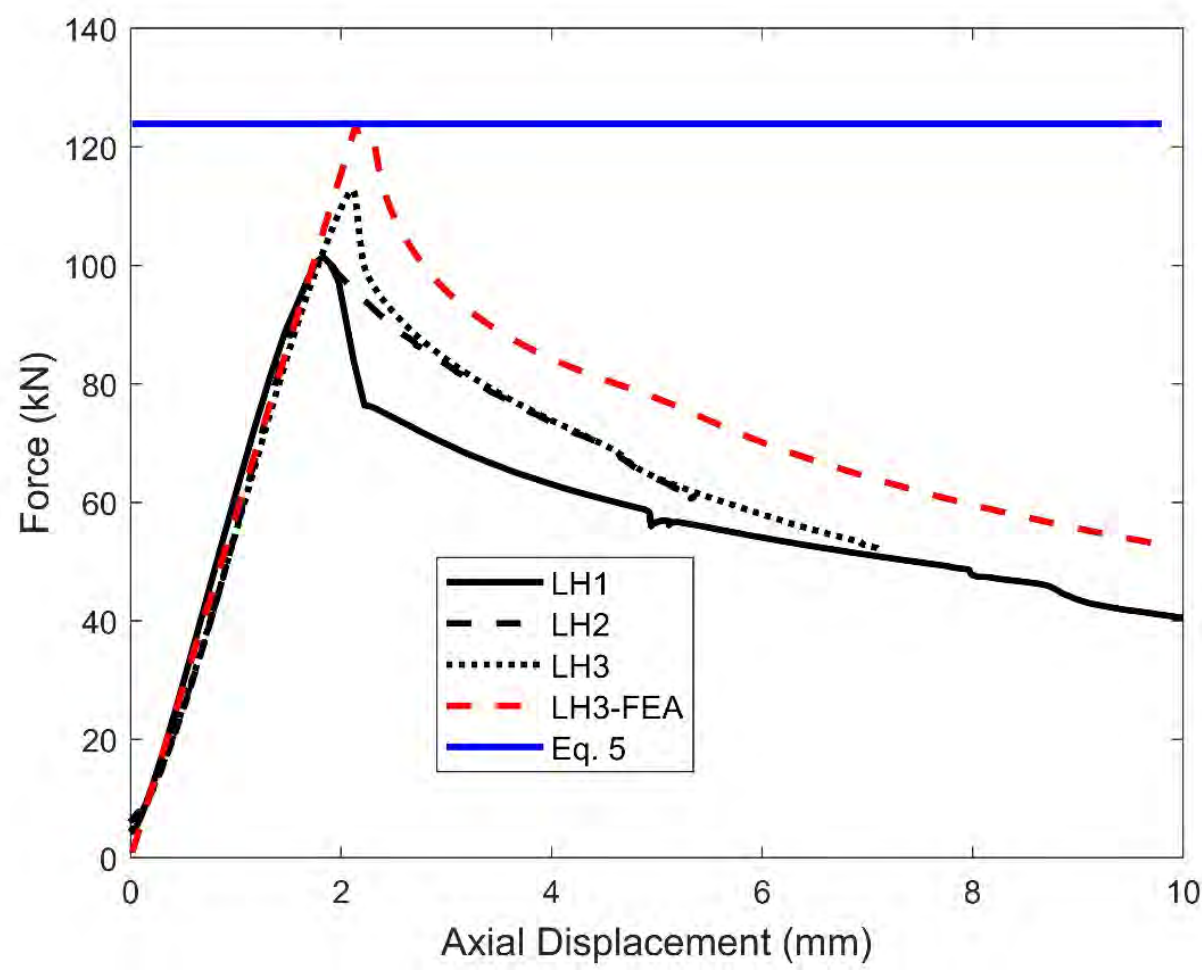

b

Figure 7. Compression test of slender TFST columns, (a) Low MOE, and (b) High MOE. 


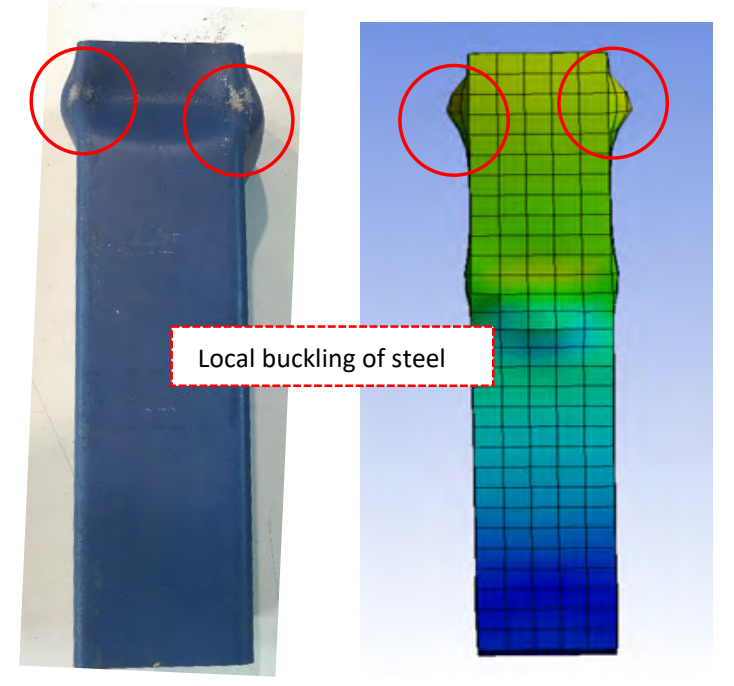

$\mathrm{a}$
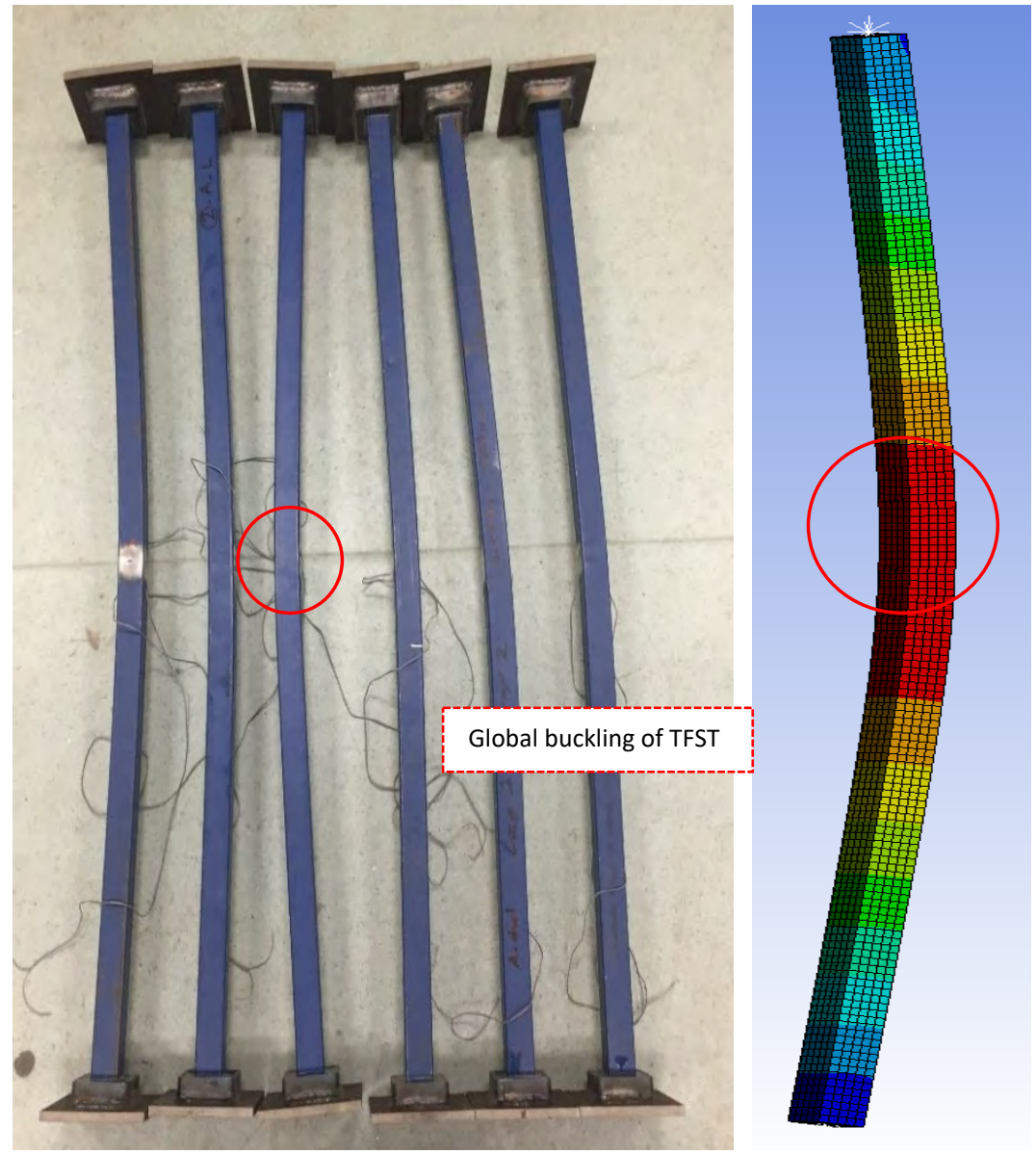

b

Figure 8. Experimentally observed and FE predicted deformed shapes of the TFST columns with, (a) $\lambda=14$, and (b) $\lambda=110$. 


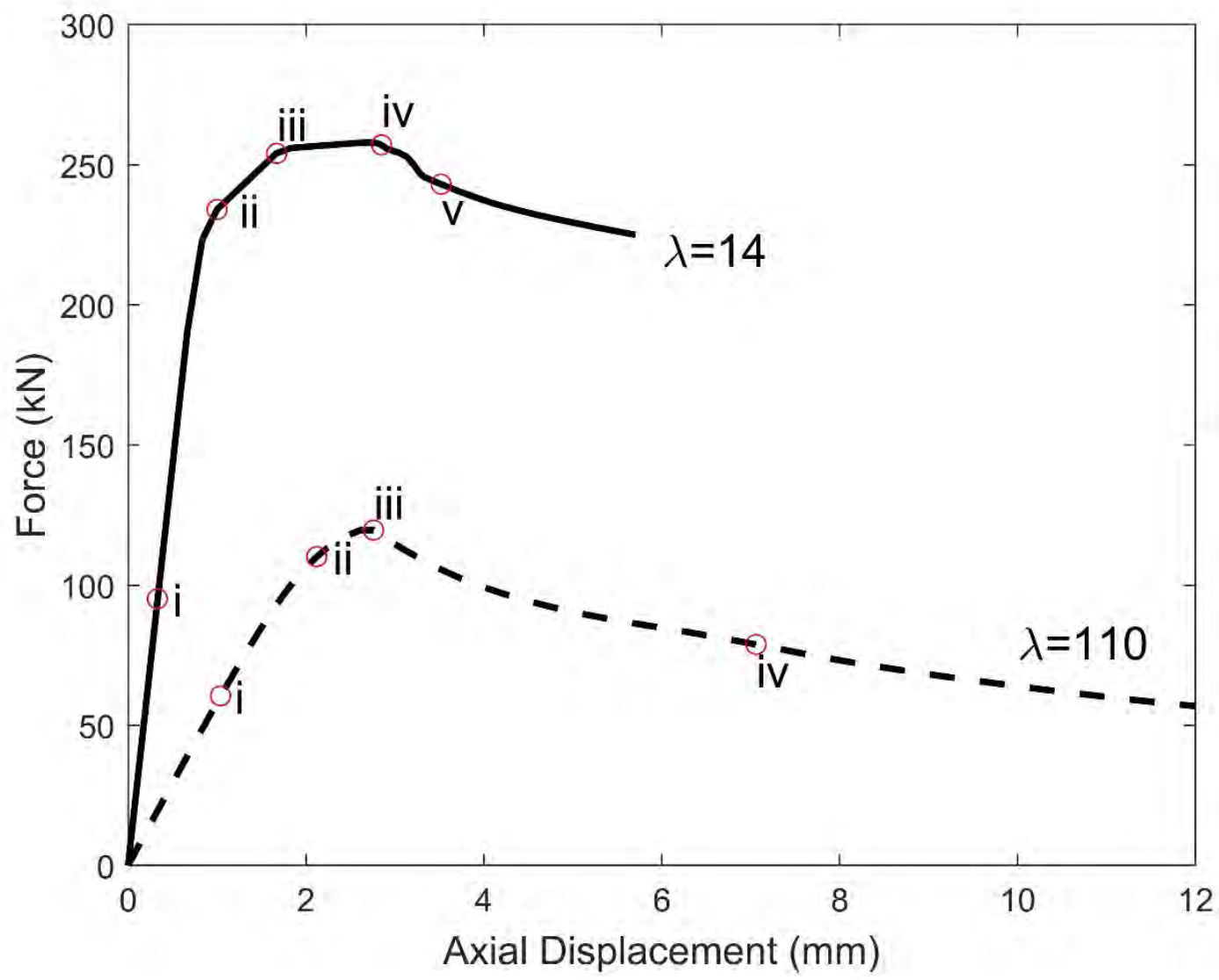

Figure 9. FEA of short and long TFST columns. Material properties and stress states are represented in Table 5. 


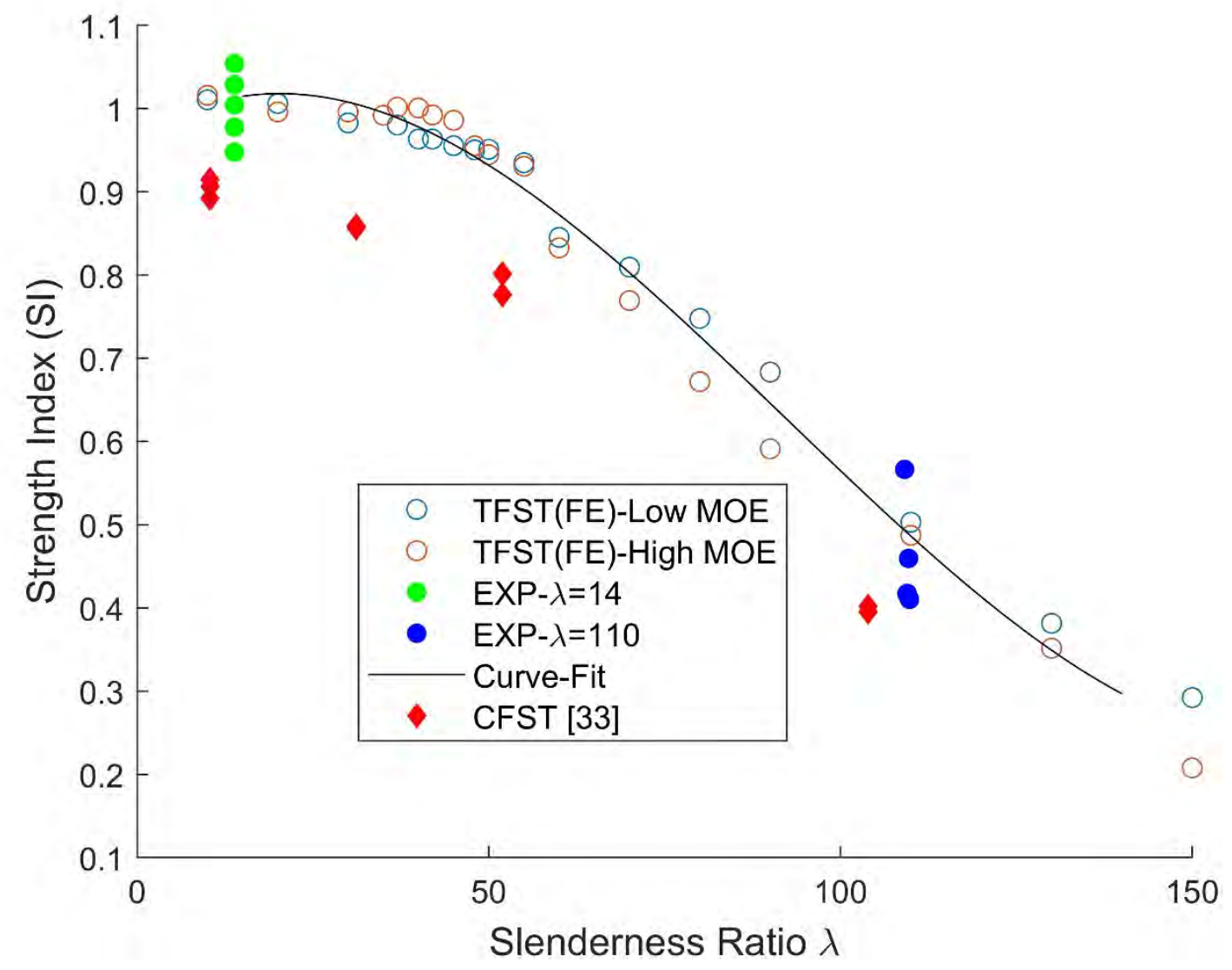

Figure 10. Slenderness curves of the low and high MOE TFST columns obtained from FEA. The current TFST experimental results and those of concrete filled (CFST) columns [33], are also shown. 